\title{
PRIMEIRA REFLEXÃO SOBRE O NOVEL REGIME JURÍDICO DAS CONTRA-ORDENAC̣ÕES ECONÓMICAS
}

\author{
ALEXANDRA VILELA \\ PROFESSORA ASSOCIADA DA ULP E DA ULHT \\ INVESTIGADORA DO CEAD
}

\begin{abstract}
This article reflects on the new Legal Framework of Economic Offences that recently entered into force. We also analyze some norms, rules, and principles, which are compared to that of the Portuguese Regulatory Law.
\end{abstract}

KEYWORDS: offence; economic offence; fine; sanction.

SUMÁRIO: 1.- Os antecedentes do diploma; 2.- Algumas observações; 3.- A conciliação prática, em sede de interpretação do novo RJCE, com os diplomas sectoriais e com o RGCO; 4.- Reflexões finais (em especial, quanto à coima).

KEYWORDS: Contra ordenação; contra ordenação económica; coima; sanção.

RESUMO: No presente artigo, é feita uma reflexão sobre o novo Regime Jurídico das Contra ordenações Económicas que entrou recentemente em vigor. Analisam se algumas normas e alguns institutos e é feito o confronto de algumas dessas normas e desses institutos com os semelhantes do Regime Geral das Contra ordenações.

\section{Os Antecedentes do Diploma}

A fazer fé no Programa Simplex+17 2, do Governo português, verificamos que foi sua pretensão implementar a medida denominada "Informação contraordenacional económica + acessível" ${ }^{3}$, tendo em vista a criação de um "ponto único de acesso online", para aí concentrar "a informação sistematizada respeitante às contraordenações económicas e correspondentes coimas, que se encontram dispersas por diversos diplomas, facilitando o seu acesso aos agentes económicos". Com efeito, dizia se, em sede desse documento, que tal "sistematização permitirá avaliar a necessidade de aprovação de um regime jurídico para as contraordenações económicas, que estabeleça um procedimento geral e garanta a uniformização das molduras sancionatórias aplicáveis" 4 . Já em sede do Preâmbulo do DL n. ${ }^{\circ}$ 9/2021, de 29 de Janeiro, que veio, então, a instituir o "Regime Jurídico das Contraordenações Económicas" (RJCE), reiterando, e assim concretizando, a sobredita medida constante do Programa Simples +17, afirma se que o desiderato deste diploma é, precisamente, proceder à aprovação de um novo diploma das contra ordenações económicas, tendo em vista, entre outros objectivos, a "uniformização e a simplificação das regras dos regimes contraordenacionais aplicáveis em matéria de acesso e exercício de atividades económicas, ao longo das cadeias de produção e distribuição, acautelando não só a eficiência desejada quanto à tramitação dos processos de contraordenação, mas também estabelecendo um regime substantivo e regime adjetivo comuns aos ilícitos contraordenacionais" 5

Ora, como já resulta do que vai dito, podemos verificar que o âmbito subjectivo de aplicação do novo diploma das contra ordenações económicas cinge se exclusivamente às que sejam legalmente qualificadas como económicas, nos termos do n. ${ }^{\circ} 1$ do artigo $1 . \therefore$ Deste modo, e para que dúvidas não restem, o n. 2 de tal artigo 1. dá nos a noção de contra ordenação económica, como sendo "todo o facto ilícito e censurável que preencha um tipo legal correspondente à violação de disposições legais e regulamentares, relativas ao acesso ou ao exercício, por qualquer pessoa singular ou coletiva, de atividades económicas, nos setores alimentar e não alimentar e para o qual se comine uma coima". Expressamente, e atendendo ao n. ${ }^{\circ} 3$ do já referido artigo $1 .{ }^{\circ}$, são excluídas da noção de contra ordenações económicas as seguintes: a) as ambientais; b) as financeiras; c) as da concorrência; d) as das comunicações e, por fim, e) as fiscais e aduaneiras e da segurança social.

Este, pois, o pórtico de entrada do RJCE, regime que teve uma vacatio legis de seis meses, pelo facto, pensamos nós, de ter alterado perto de cento e setenta 
DOI: 10.46294/ulplr-rdulp.sivla8

diplomas legais, desde a Lei n. ${ }^{\circ}$ 55/90, de 5 de Novembro, que cria a marca colectiva de proveniência para os bordados da Região Autónoma da Madeira, passando pelo $\mathrm{DL} \mathrm{n.}$. 28/84, de 20 de Janeiro, onde se encontram previstas as infracções contra a economia e contra a saúde pública, pelo DL n. ${ }^{\circ}$ 166/2013, de 27 de Dezembro, que aprova o regime aplicável às práticas individuais restritivas do comércio, por tantos e tantos outros, terminando na legislação de combate à droga. Vastas e diferentes matérias, enfim, agora espartilhadas em mais um diploma legal que persiste em ignorar o Regime Geral das Contra ordenações (RGCO), apenas se lembrando dele para o erigir em subsidiário, já na sua parte final. Na verdade, dizíamos que o ignora, porque ora repete normas de sentido convergente com ele, ora as cria em sentido divergente, mas fazendo dele, ainda assim, legislação subsidiária liá assim em anteriores diplomas, como nos dá conta AZEVEDO, 2020, 45 e seguinte).

Dito isto, vejamos, agora, apenas, alguns dos seus preceitos, pois que tal diploma é credor de uma análise mais aturada. Desde logo, para tentarmos perceber se a harmonização e a simplificação, desideratos por si assumidos no âmbito dos diplomas aqui em causa, foram ou não logrados.

\section{Algumas Observações}

Uma primeira conclusão que é possível ser retirada da análise do DL n. ${ }^{\circ}$ 9/2021, de 29 de Janeiro, que aprova o RJCE, é que ele não constitui uma macro revisão do direito contra ordenacional, mas apenas, e tão-só, uma pequenina revisão. $\mathrm{Na}$ verdade, o seu legislador apenas alterou sectores, ou ramos, daquele direito, por assim dizer, referentes à economia doméstica, isto é, segmentos de diplomas legais que, embora abranjam diferentes sectores económicos (e não só, com acima se viu), não se encontram tão fortemente vinculados ao direito da União Europeia. Enfim, o DL n. ${ }^{\circ}$ 9/2021 não toca no Regime Jurídico da Concorrência, no Código de Valores Mobiliários, no Regime Geral das Instituições de Crédito e Sociedades Financeiras, entre muitos outros que aqui poderíamos elencar. Quanto a estes, iá se sabe, o Estado Português pouca autonomia tem, e há muito que está praticamente vergado à política legislativa definida em sede da União Europeia. Numa só palavra: os grandes sectores regulados, aqueles que surgem aquando da emergência e desenvolvimento das crises económico financeiras, e onde maioritariamente se integram aquelas contra ordenações a que ACHENBACH, em finais do século XX, designou "grandes" contra ordenações susceptíveis de produzirem um dano social relevante» (ACHENBACH, 2008, 9, e VILELA, 2013, 233), essas contra ordenações estão de fora deste diploma, pela razão que acima indicámos.

Bem sabemos, pois, que os regimes jurídicos desses sectores foram concebidos, quase de forma uniforme, pela União Europeia, embora os diplomas dali emanados concedam relativa liberdade ao legislador nacional para criar o tipo de ilícito que melhor entender e, desse modo, os sancionar seja com pena, seja com coima, seja, ainda, com sanção administrativa. Prova dessa mesma relativa liberdade é o caso, por exemplo, de, entre nós, praticamente todo o direito da concorrência se deixar subsumir ao direito de mera ordenação social, enquanto, em outros ordenamentos jurídicos da União Europeia, é o direito penal que o regulamenta, embora com posições críticas da parte de alguma doutrina nacional (MARQUES, 2019, 449 e seguintes).

Note se, todavia, que, no específico domínio da União Europeia, em momento algum, podem ser obliterados o princípio da efectividade e os seus subprincípios da prevalência do Direito da União Europeia e o da uniformidade na aplicação, entre outros (GORJÃO HENRIQUES, 2021, 353 e 358 398).

Não que os ilícitos de mera ordenação social económicos contemplados neste novo regime não se possam apresentar como igualmente gravosos sob o ponto de vista pecuniário, pois basta olharmos para as molduras contra ordenacionais abstractas, previstas em sede do artigo 18. ${ }^{\circ}$ do RJCE, para assim concluirmos.

Mas não só essas ficam de fora do RJCE, pois que também são dele excluídas aquelas que representam uma verdadeira manifestação de autoridade do Estado, isto é, as contra ordenações fiscais e as da segurança social, afinal, dois redutos

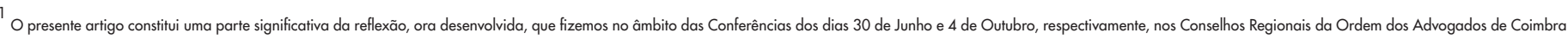
e da Madeira. Beneficiou, outrossim, da leitura crítica da Mestre Diana Simas, a quem agradecemos, e encontra se escrito ao abrigo do anterior acordo ortográfico.

2 Consultável em https://simplex.gov.pt/simplexmais/app/files/967ff098fcc6a0f72d2af69cfab39e70.pdf

3 Cf. o mencionado documento, na sua p. 56.

${ }^{4}$ Cf., de novo, o supra referido documento, na mesma p. 56.

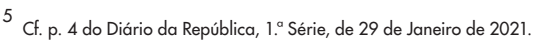


onde o Estado português pode, ainda, duramente, exercer o seu ius puniendi laqui, obviamente, entendido em sentido lato), de forma autónoma e sem se encontrar demasiadamente espartilhado. Aliás, neste sentido, recordam se as palavras de SOUSA, para quem os ilícitos de direito fiscal, no âmbito do ordenamento jurídico português, possuem autonomia perante as demais condutas violadoras, há mais de um século e meio (SOUSA, 2010, 39 e 40). A este propósito, é pertinente recordar que o próprio Regime Geral das Infracções Tributárias (RGIT), aprovado pela Lei n. ${ }^{\circ}$ 15/2001, de Junho, prevê que o seu âmbito de aplicação se estenda não apenas às normas reguladoras das prestações tributárias, dos regimes tributários, dos aduaneiros e fiscais, dos benefícios fiscais e das franquias aduaneiras, bem como às normas das contribuições e prestações relativas ao sistema de solidariedade e segurança social (artigo $1 .{ }^{\circ}$, n. 2) ) É, outrossim, certo que as contra ordenações da segurança social sempre foram excluídas de tal regime (SOUSA, 2010, 59), encontrando se, presentemente, previstas e reguladas pela Lei n. ${ }^{\circ}$ 107/2009 de 14 de Setembro.

Uma segunda conclusão é a de que também não estamos perante uma alteração ao Regime Geral das Contra ordenações (RGCO), aprovado pelo DL n. ${ }^{\circ} 433 / 82$, revisão essa há muito reclamada pela doutrina (entre outros, veja se, a título meramente exemplificativo, VILELA, 2013, 330, DIAS, 2018, 35). De qualquer modo, o novel RJCE prevê normas de sentido diferente das do RGCO, prevê outras tantas que deste não constam, legisla em sentido contrário àquele que ele dispõe, prevê novos institutos (como, por exemplo, o da reincidência) ou revê os, como em seguida iremos ver. Não obstante, o diploma referente às contra ordenações económicas apresenta uma arrumação sistemática e estrutural em tudo semelhante à do RGCO, quase que feita em decalque: também aquele se encontra dividido num Capítulo I, referente às contra ordenações económicas e da coima, e um Capítulo II, referente ao respectivo processo e, dentro deste, uma secção referente à fase organicamente administrativa e uma outra à fase judicial. Verifica se, outrossim, a mesma localização e igual conteúdo dos princípios da legalidade (artigo 2.9 ), da aplicação da lei no tempo (artigo 3.9), aplicação da lei no espaço (artigo $4 .{ }^{\circ}$ ), etc.

Com legitimidade, pode o leitor pensar que se encontra perante uma alteração ao RGCO, instituído pelo DL n. 433/82, e não perante um diploma que preveja especificamente um regime sobre contra ordenações económicas. Mas não. Estamos, mesmo, perante um diploma legislativo que aprova o regime jurídico das contra ordenações económicas e que altera "apenas" cerca de cento e setenta leis, algumas das quais contêm regimes contra ordenacionais especiais, e que, a partir dos finais de Julho, passou a ser aplicado no âmbito das contra ordenações classificadas, por esse mesmo regime especial, como económicas.

Revela se, pois, importante responder à seguinte questão: como se conciliam, como se articulam, em sede de hermenêutica jurídica, as normas dos regimes sectoriais com as do diploma das contra ordenações económicas e com as do RGCO?

\section{A Conciliação prática, em sede de interpretação do novo rịce, com os diplomas sectorias e com o RGCO}

3.1. Está visto que, mesmo escolhendo o RGCO como subsidiário, de acordo com o artigo 79. do RJCE, este último não se coíbe de prever princípios e normas cujo teor reproduzem o que se encontra naquele primeiro. Já demos o exemplo do princípio da legalidade (artigo $2 .{ }^{\circ}$ ), do princípio da territorialidade (artigo $3 .{ }^{\circ}$ ), sendo que podemos acrescentar, entre outros, a regra do concurso entre crime e contra ordenação (artigo $27^{\circ}$ ), o princípio da impugnabilidade das decisões, despachos e demais medidas tomadas pelas autoridades administrativas no decurso do processo do ilícito de mera ordenação social (artigo 45.') e do princípio da proibição da reformatio in pejus (artigo $74 .{ }^{\circ}$ ), etc.

Noutros casos, o RJCE introduz normas de sentido diametralmente oposto ao daquele mesmo RGCO, como seja, a título meramente exemplificativo, o critério de imputação da responsabilidade pelo ilícito de mera ordenação social às pessoas colectivas (artigo 7.9), a redução de $20 \%$ sobre o montante mínimo previsto para a infracção dolosa praticada, desde que tenha havido pagamento voluntário da coima (artigo $47^{\circ}$, n. $^{\circ}$ 2) e, igualmente, a alteração do prazo definido para o exercício da defesa (artigo $58 .^{\circ}$, n. $^{\circ} 2$ do RJCE), isto para darmos apenas alguns exemplos.

Mas mais ainda: com o propósito de harmonizar os regimes das contra ordenações económicas, o DL n. 9/2021, de 29 de Janeiro, que aprova o RJCE, altera os já mencionados perto de cento e setenta diplomas, para, em quase todos, proceder à classificação das contra ordenações em leves, graves e muito graves, e para alterar as normas referentes à punibilidade da tentativa e da negligência, no sentido de que estas passam a ser puníveis nos termos do RJCE, e para declarar que este último se aplica subsidiariamente aos respectivos diplomas.

Esta última alteração provocada pelo mencionado DL n. ${ }^{\circ}$ 9/2021 merece, desde já, uma observação atenta, na medida em que não se compreende a sua necessidade de previsão expressa, em cada uma das leis (aqui, obviamente, em sentido gerall, dizendo que o RJCE é subsidiário, ou seja, que se aplica apenas quando o diploma em concreto não dispuser acerca de determinada matéria, porque, efectivamente, o próprio artigo $78 .^{\circ}$, não só dispõe, no seu n. ${ }^{\circ} 1$, que os regimes jurídicos sectoriais que possuam regimes específicos prevalecem sobre o RJCE, como também o seu n. 2 dispõe que este último se aplica subsidiariamente quando tal aplicação se encontre expressamente determinada naqueles regimes. 
Ou seja: qual a razão pela qual, depois de o intérprete saber que o regime jurídico específico de uma contra ordenação económica prevalece sobre qualquer outro, qual a razão, dizíamos, para que o RJCE venha dispor que ele só é aplicável subsidiariamente, se tal estiver previsto no regime específico de determinada contra ordenação? Afinal, não se pretende simplificar? Se assim é, de duas, uma: ou o regime económico específico tem norma própria e ela é aplicável, e a norma do RJCE não faz sentido; ou, não a tem, e o regime ali ausente deve ser procurado, obviamente, naquele que se assume, agora, como o Regime Geral das Contra ordenações Económicas.

3.2. Tomando em conta os normativos acabados de referir, e tendo igualmente presente o teor do artigo $790^{\circ}$ do RJCE, segundo o qual em tudo o que não se encontrar previsto neste último aplica se o RGCO, na sua redacção actual lé caso para se perguntar, qual a razão pela qual se haveria de aplicar uma redacção desactualizada, já revogada, ou modificada e, por isso, que já não está em vigor), importa, dentro deste cenário, perceber como interpretar e, depois, aplicar tão simples diploma, cujo desiderato é o da uniformização legislativa em matéria de contra ordenações económicas.

3.2.1. Partamos, pois, para um exemplo em concreto, colhido a partir do $D L n$. 28/84, referente às infracções antieconómicas e contra a saúde pública, diploma, agora, também debaixo da alçada do regime das contra ordenações económicas, de acordo com o artigo 16..$^{\circ}$ do RJCE: suponhamos que uma pessoa jurídica foi acusada de ter cometido, em dois momentos distintos, a contra ordenação antieconómica prevista no seu artigo 58. ${ }^{\circ}$, contra a genuinidade, qualidade ou composição de géneros alimentícios e aditivos alimentares, a primeira a título de dolo e segunda a título de negligência $\left(n^{\circ}{ }^{\circ} 2\right.$ do referido artigo 58. $)$; que, depois, é condenada e, por fim, que ela pretende impugnar a decisão da autoridade administrativa.

Atendendo a este quadro factual, bem como ao novo RJCE, a primeira preocupação que surge, face ao facto comummente aceite de que as contra ordenações negligentes são puníveis excepcionalmente $\left(n .^{\circ} 1\right.$ do artigo $8 .^{\circ}$ do RGCO), será, obviamente, verificar se a sobredita contra ordenação pode ser cometida a título de negligência. Assim, e anteriormente ao DL n. 9/2021, ficávamos logo a saber, pela leitura do n. 2 do já mencionado artigo 58. do DL n. 28/84, que a negligência, no caso da contra ordenação em apreço, era punível. Agora, não. Eis, pois, como chegar à resposta: esse mesmo preceito do DL n. ${ }^{\circ} 28 / 84$ (n. 2 do artigo 58.') passou a dispor, depois da alteração que the operou o DL n. $9 / 2021$, que a tentativa e a negligência são puníveis nos termos do RJCE. Mas, para que não restem dúvidas, o n. ${ }^{\circ} 2$ do artigo 1. do DL n. ${ }^{\circ} 28 / 84$, saído da alteração operada pelo RJCE, diz, outrossim, que às "contraordenações económicas previstas neste diploma é aplicável subsidiariamente o RJCE".

Deste modo, impõe se ao intérprete recorrer ao tal diploma uniformizador e concluir, da leitura do n. 1 do artigo $8 .^{\circ}$ do RJCE, que a negligência, nas contra ordenações económicas, é punível "nos casos expressamente previstos", em uma redacção em tudo idêntica à do n. ${ }^{\circ} 1$ do artigo $8 .^{\circ}$ do RGCO. Isto é, confirma se a regra da punibilidade excepcional da negligência do direito de mera ordenação social (ALBUQUERQUE, 2011, 61), assim restringindo a punição desta contra ordenação a título de dolo. Por princípio, tal facto não pode deixar de merecer - nosso aplauso, pois que tal disposição contribui para diminuir os excessos de contra ordenacionalização. No entanto, o que é facto é que não deixa de ser uma medida tomada contra a corrente daquela que tem vindo a ser seguida, qual seja a de punir a negligência enquanto regra.

Cientes, pois, de que os regimes sectoriais que prevejam um regime contra ordenacional específico prevalecem sobre o RJCE, conforme já vimos que nos diz o artigo $78 .^{\circ}$, n. ${ }^{\circ} 1$ do RJCE, procuremos, agora, qual o critério de imputação da responsabilidade da pessoa jurídica a escolher para efeitos de aplicação no caso em análise. Para tanto, revela se necessário percorrer o DL n. ${ }^{\circ}$ 28/84 e verificar se aí existe, ou não, tal critério, pois, em caso de resposta negativa, aplicar se á o regime previsto no artigo $7^{\circ}$ do RJCE, que prevê um critério de imputação de responsabilidade contra ordenacional muito mais amplo do que o do artigo $7^{\circ}$ do RGCO, posto que, há mais de vinte anos, SERRA escreveu que tal critério não serve os desideratos dos princípios da igualdade e da justiça, constituindo, desse modo, um tratamento de favor dado às pessoas jurídicas (SERRA, 1999, 192 e seguintes e 206 e seguintes. Neste sentido, veja se igualmente o que dizemos em VILELA, 2020, 395 e seguintes).

Sucede, porém, que, logo no artigo 3. do diploma das infracções antieconómicas e contra a saúde pública, topamos com um critério próprio para os mencionados fins, razão pela qual o do artigo $7^{\circ}$ do RJCE é afastado pelo artigo $3 .^{\circ}$ do DL n. 28/84, ao abrigo do supra-referido n. ${ }^{\circ} 1$ do artigo 78. do RJCE. E, deste modo, está, assim, encontrado o critério de imputação da responsabilidade contra ordenacional à pessoa jurídica. 
Todavia, aqui, julgamos ser pertinente fazer uma pequenina observação e que é a seguinte: dissemos acima que o artigo $7^{\circ}$ do RGCO consagra um critério muito restritivo da responsabilidade contra ordenacional das pessoas colectivas. Pois bem: comparando esse critério com o previsto no $\mathrm{DL}$. ${ }^{\circ}$ 28/84, verificamos que o deste último diploma é um pouco mais amplo. No entanto, a verdade é que, ainda assim, nos dias de hoje, também este se revela igualmente restritivo (VILELA, 2020, 406 409). Deste modo, não se percebe a razão pela qual o legislador do DL n. 9/2021 optou por manter o critério do DL n. 28/84, quando o previsto no RJCE é bem mais amplo (se adequado ou não, veremos em outra sede).

Continuando, depois, pela impugnação judicial, importa que a infractora analise as regras a ela referentes. Ora, neste ponto, impõe se, novamente, o regresso ao DL n.․ 28/84, o qual, na sua secção III (artigos $73^{\circ}$ a $80 .^{\circ}$ ), é demasiadamente parco quanto a disposições específicas sobre o tema, razão pela qual se impõe o regresso ao RJCE.

Já sabemos que o RJCE se aplica subsidiariamente quando esteja expressamente previsto no regime sectorial específico $\left(n .^{\circ} 2\right.$ dos seus artigos $78 .^{\circ}$ e $\left.79.9^{\circ}\right)$, o que, na presente situação, se verifica, atendendo ao n.. 2 do artigo 1. ${ }^{\circ}$ do DL n. $28 / 84$. Vale por dizer que o processo de impugnação da decisão condenatória se rege pelos artigos $68^{\circ}$ a $75^{\circ}$ do RJCE.

Mas imaginemos que a autoridade administrativa manteve a sua decisão (ou seja, não a revogou, nem total, nem parcialmente, conforme the permite $\circ$ n. 2 do artigo $73^{\circ}$ do RJCE) e, nessa sequência, enviou os autos ao Ministério Público, igualmente, nos termos daquele mesmo artigo $73 .^{\circ}$. Aquele, por sua vez, não retirou a acusação, conforme the permite o n. 4 do já mencionado artigo $733^{\circ}$, hipótese em que o processo deverá ser necessariamente remetido para o Tribunal. No entanto, após compulsarmos as regras processuais do RJCE, referente à fase judicial, o que se conclui é que da norma referente ao envio dos autos ao Ministério Público (artigo 73.9) "salta se", de imediato, para a proibição da reformatio in pejus. $\bigcirc$ mesmo é dizer que a tramiłação ulterior da impugnação, em ambiente judicial, não consta do RJCE. Por isso, impõe se, agora, amparados no RJCE, ver qual o diploma a consultar em seguida.

Como já dissemos, nos termos do artigo 79. ${ }^{\circ}$ o direito subsidiário do RJCE é o RGCO, e, por assim ser, depois de termos manuseado, para efeitos de recurso, - DL n. 28/84, bem como o RJCE, impõe se, agora, um "salto" ao RGCO, na medida em que é nesse diploma que vamos encontrar a tramitação ulterior do processo. E eis nos a aplicar, novamente, um diploma que, afinal, parece que já não serve para nada e que tudo complica. Eis nos, pois, a termos necessidade de analisar os artigos 63. a 75. do RGCO. Mas não só, porque, compulsado o artigo 66. do RGCO, verifica se que teremos, ainda, de analisar o DL n. 17/91, de 10 de Janeiro, onde se encontra regulado o processamento e julgamento das contravenções e das transgressões na audiência em primeira instância, a fim de sabermos quais as regras que a ela se aplicam. Sucede, porém, que, já no ano de 2013, nos insurgíamos contra a remissão do artigo 66. do RGCO, para o DL n. 17/91, pelo facto de a mesma ser descabida, que dizer, ao presente momento, volvidos praticamente dez anos sobre o que então escrevemos (VILELA, 2013, $491493)$ ?

Em consequência, onde anteriormente era apenas necessário o estudo do diploma sectorial ou específico e o RGCO, agora, o intérprete/aplicador terá de trabalhar com três diplomas: primeiro, com o regime sectorial específico, depois, com o RJCE, em seguida, com o RGCO, depois, ainda, com aquele que se refere às "normas relativas ao processo das transgressões e contravenções", qual seja o DL n. ${ }^{\circ}$ 17/91, de 10 de Janeiro. Na pior das hipóteses, com o próprio Código Penal (CP) ou com o Código de Processo Penal (CPP), pois que estes continuam a ser os direitos subsidiários do regime geral.

Como se vê, não corresponde necessariamente à verdade que este diploma sirva o desiderato da simplificação dos regimes contra ordenacionais ao longo das cadeias de produção e de distribuição.

Acresce que também não se percebe qual a razão pela qual o RJCE foi tão inovador quanto às regras que introduziu nos artigos $43 .^{\circ}, 46^{\circ}, n^{\circ}$ 1, d) e artigo $61 . \circ$, respectivamente, quanto à tramitação electrónica, às notificações por correio electrónico, à inquirição por meios não presenciais, assim legislando ao arrepio do RGCO, e, em contrapartida, no âmbito da fase judicial (artigos 68. a $75 .{ }^{\circ}$ ), tenha sido tão parco em inovações legislativas e em simplificação dessa fase processual, ao ponto de manter em vigor um diploma de onde constam as "normas relativas ao processo das transgressões e contravenções".

Por assim ser, e sem prejuízo de este novo Regime Jurídico ser louvável em alguns pontos, certo é que melhor fora que o legislador tivesse procedido à revisão do RGCO, contido no DL n. 433/82. E verdade seja dita: muitas das normas que inseriu no novo diploma sobre as contra ordenações económicas poderiam bem ser inscritas na revisão ao referido regime geral. $\bigcirc$ legislador, ao fazer aprovar um diploma que se assemelha a uma revisão ao RGCO, em vez de proceder à sua revisão, parece, assim, que seguiu por atalhos. Resta ver se não arranjará "trabalhos". 


\section{Reflexões finais (em especial, quanto à coima)}

4.1. Podíamos terminar, neste preciso ponto, a primeira análise que nos propusemos fazer ao RJCE. No entanto, confessamos sentir uma certa necessidade em evidenciar um outro ponto de tal regime jurídico que nos preocupa igualmente e que, por isso, não queríamos deixar de abordar. Trata se de uma questão que estudámos no passado e que voltou a merecer a nossa reflexão oral e escrita ${ }^{6}$ e que, a nosso ver, é das mais importantes e delicadas matérias no âmbito de um qualquer direito sancionatório, sobretudo neste, o direito de mera ordenação social, onde a sanção pecuniária principal (a coima) pode atingir valores astronómicos. Assim, sem que nos pretendamos alongar muito quanto ao sobredito nódulo problemático, não podemos deixar de escrever umas breves linhas a propósito do modo como se identificam as respectivas molduras contra ordenacionais abstractas, quer para as pessoas singulares, quer para as jurídicas e, depois, quanto à determinação do valor concreto da coima, em alguns casos particulares. Estas considerações enquadram se, no nosso jeito de ver este ponto, no respeito que esta delicada e sensível matéria deve aos princípios da legalidade, ${ }^{7}$ da determinabilidade e da própria separação dos poderes, como decorrência do da legalidade. Vale por dizer: os ilícitos de mera ordenação social e as respectivas molduras sancionatórias devem estar previstos na lei, de forma que cumpra com aqueles princípios, vedando, pois, em momento ulterior, que seja o aplicador da sanção a determiná la. Na verdade, só sabendo qual o mínimo e o máximo do valor da coima a aplicar, é que o seu autor é livre de escolher, conscientemente, entre praticar, ou não, o ilícito de mera ordenação social e, assim, assumir responsavelmente o valor da coima. Dito isto, abalancemo nos, pois, para umas breves considerações, a fim de, em momento posterior, concluirmos.

4.2. Neste enfiamento, não podermos concordar, desde logo, com o critério de determinação das molduras contra ordenacionais que leva em consideração a gravidade da contra ordenação (artigo 17. do RJCE) e que fixa, posteriormente, uma moldura contra ordenacional abstracta conforme o ilícito seja leve, grave ou muito grave. Esta técnica que, de resto, não é inédita no direito de mera ordenação social (cf., por exemplo, o artigo 388. do Código de Valores Mobiliários), conduz nos à ideia errada de que todas as contra ordenações leves, por um lado, graves, por outro, e ainda, muito graves, devem ser sancionadas com molduras contra ordenacionais iguais. A nosso ver, esta técnica de agrupar estas infracções consoante uma gravidade que, muito provavelmente, não foi identificada caso a caso, e daí partir para o mesmo arco sancionatório, conduz nos à conclusão errada de que todos os ilícitos leves possuem a mesma gravidade entre eles, o mesmo acontecendo com os graves e os muito graves. Temos dúvidas que assim seja e que se deva usar um critério de identificação da coima, passe a expressão, "por atacado".

Por outras palavras: vistas e agrupadas as contra ordenações, como faz o artigo 18. ${ }^{\circ}$, a fim de thes fixar o montante das coimas, parece que possuem todas, em abstracto, a mesma gravidade, o que não é verdade. São assim gorados os objectivos do legislador, quando, no Preâmbulo do novo regime das contra ordenações económicas, diz que se introduziu um juízo de proporcionalidade na aplicação das coimas, graças à já aludida classificação.

4.3. Num segundo momento, e ainda tendo em vista a definição da moldura contra ordenacional abstracta, mas agora especificamente a das pessoas jurídicas, o legislador classificou as em microempresa, pequena empresa, média e grande empresa, à semelhança do que faz o artigo 100. do Código de Trabalho, aprovado pela Lei n. $7 / 2009$, de 14 de Setembro. A partir daí, conjuga a gravidade da contra ordenação (artigo $17^{\circ}$ e 18.9) com a dimensão da pessoa jurídica (artigo 19.9), alcançando, desse modo, a específica moldura contra ordenacional abstracta a aplicar à pessoa jurídica.

Ao presente momento, em pleno século XXI, é difícil, muito difícil mesmo, classificarmos a grandiosidade de uma empresa exclusivamente em função do seu número de trabalhadores, aqui se incluindo os assalariados, os equiparados a assalariados, os proprietários gestores e alguns sócios, como o faz o n. 2 do artigo 19. do RJCE. Diríamos mais: difícil e arriscado, pois estes novos tempos, os da pandemia que teima em não nos abandonar, têm nos mostrado à saciedade, o que, de resto, já era do nosso conhecimento: lucros astronómicos com poucos trabalhadores, prejuízos elevadíssimos com muitos trabalhadores.

Aliás, ainda a este propósito, é pena que o legislador do RJCE, embora afirme, no Preâmbulo do respectivo diploma, que a distinção da empresa, de acordo com a sua dimensão, leva em consideração "no essencial" "os critérios constantes

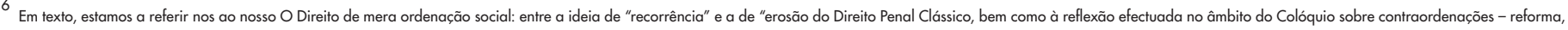
precisa se? -, organizado pelo Fórum Penal, no Palácio da Bolsa, Porto, no dia 18 de Setembro de 2017, e que será publicado, embora de forma desenvolvida, em breve, no Livro de Homenagem ao Professor Doutor Augusto Silva Dias.

7 A propósito do princípio da separação dos poderes e a sua relação com o da legalidade no âmbito do Direito Penal, cf. FARIA COSTA (2018), Direito Penal, Lisboa: Imprensa Nacional Casa da Moeda, pp. 136 138.

8 Cf. p. 5 do Diário da República onde se encontra publicado o diploma em causa.
} 
da Recomendação n. 2003/361/CE, da Comissão Europeia, de 6 de maio de 2003"8, relativa à definição de pequenas e médias empresas, para efeitos de aplicação de políticas comunitárias no interior da Comunidade e do Espaço Económico Europeu, ignore, por completo, a segunda parte do n. 1 do artigo 1. , da mencionada Recomendação, onde se refere o montante volume de negócios anual de cada empresa.

É um facto que estamos perante um diploma da União Europeia cujo âmbito de aplicação são as políticas comunitárias e que, por tal facto, não guarda relação com o tema aqui tratado, sendo, outrossim, certo que estamos apenas perante uma Recomendação, acto não vinculativo e que é adoptado, neste caso, por iniciativa da Comissão. Vale por dizer: estamos perante um diploma legal comunitário que não vincula os Estados Membro (DUARTE, 2021, 310) e que não tem relação com o tema que aqui nos traz. Tudo isso é certo. No entanto, também não deixa de ser verdade que qualquer diploma, sobretudo os de carácter sancionatório, no momento da sua elaboração, devem ser imbuídos de uma ideia de justiça, por forma a que, na hora da sua aplicação, se cumpram, entre outros princípios basilares de qualquer direito sancionatório, os da justiça do caso concreto e da igualdade, este último nas suas duas vertentes, a horizontal e a vertical. Isto, tanto mais que é o próprio legislador que invoca, no Preâmbulo, a mencionada Recomendação.

Deste modo, se já está demonstrado que o número de trabalhadores não tem, presentemente, uma relação directa com a dimensão económica da empresa e se o legislador do RJCE pretendeu chegar a uma coima que leve em conta a dimensão económica da empresa (só assim ela será justa e adequada), então, não se deveria ter atido exclusivamente ao critério do número de trabalhadores para, assim, chegar a uma moldura contra ordenacional. Deveria, isso sim, conjugar este último critério com os demais usados na Recomendação acima referida, quais sejam o do volume de negócios anual. Perdeu se, pois, uma oportunidade para se lançar mão de um critério mais fidedigno quanto à verdadeira dimensão económica de uma empresa.

4.4. Não se pense, porém, que os problemas em matéria directamente relacionada com os montantes mínimos e máximos da coima se ficam por aqui, pois que o legislador do RJCE, no n. 3 do artigo 19. , parece ignorar os princípios da legalidade e da determinabilidade da coima, quando recorre a uma presunção segundo a qual, quando não se consegue apurar a dimensão da empresa, para efeitos de aplicação da coima, aplica se a moldura contra ordenacional prevista para as médias empresas, diz a segunda parte do n. 3 do artigo em questão, "sem prejuízo de poderem ser considerados novos elementos de facto que conduzam à alteração dessa classificação, trazidos aos autos por indicação do arguido, ou que sejam do conhecimento oficioso da autoridade administrativa que proceda à instrução ou decisão do processo".

De outro modo: a arguida apenas toma conhecimento de qual é, ao certo, a moldura contra ordenacional em que incorre depois da prática da infracção, sendo certo, ainda, que pode ficar sujeita à apreciação da sua dimensão pela própria autoridade administrativa, a qual, certamente, terá tendência a considerar a pessoa jurídica de maior dimensão do que ela, na verdade, é. Se a arguida quiser contrariar esta técnica de identificação da moldura, pois, então, ela que leve aos autos elementos que o permitam fazer. Mas, se, ainda assim, não se chegar a fazer prova de que ela é uma pequena empresa, quando, na realidade, o é? Pois bem: nesse caso, a moldura contra ordenacional será a que se aplica às médias empresas.

Mais uma vez, mesmo correndo o risco de sermos repetitivos face ao que já anteriormente escrevemos, em matéria de identificação das molduras contra ordenacionais abstractas, valem, para além do princípio da legalidade, o da determinabilidade (DIAS, 2018, 71 a 76). Este que permite ao infractor saber qual é o montante da coima em que incorre previamente à comissão da infracção.

Ainda a propósito destes princípios, diga se que é de estranhar a vaguidão do artigo 22. do RJCE, no que diz respeito à agravação especial da coima, cuja conformidade com os princípios da legalidade e da determinabilidade consideramos, igualmente, colocada em causa. Na verdade, aqui não é a lei que fixa o limite máximo da coima, por exemplo, em 48.000,00 € e 180.000, 00 $€$, consoante estejamos, respectivamente, perante uma contra ordenação grave ou muito grave, praticada por uma grande empresa (artigo $18{ }^{\circ}$, b), subalínea v) e alínea c), v). Quem a define é, sim, a entidade administrativa que aplica a coima. Se não, vejamos o teor do artigo 22.: "os limites mínimo e máximo da coima a aplicar às contra ordenações graves e muito graves são elevados para o dobro quando o agente tenha causado dano na saúde ou na segurança das pessoas". Ora, este novo limite máximo, encontrado graças à conjugação do artigo $18^{\circ}{ }^{\circ}$, com $\circ 22 .^{\circ}$, repetimo lo, viola não apenas o princípio da legalidade, como também o da própria separação dos poderes, porque é o aplicador do direito que fixa a nova moldura abstracta.

4.5. Uma última palavra quanto às coimas, mas, desta feita, atendendo especificamente às que não foram pagas atempada e voluntariamente e que, por esse motivo, carecem de ser cobradas de forma coerciva. Dentro desta medida, é importante levarmos em conta o artigo 64. ${ }^{\circ}$ do RJCE, norma em que o legislador não resistiu "chamar à liça" aquela vertente do Estado mais vigorosa e musculada, qual seja a Autoridade Tributária e Aduaneira (AT). Deste modo, se, em sede do artigo 89. do RGCO, se dispõe que o processo executivo, para pagamento 
DOI: 10.46294/ulplr-rdulp.siv la8

coercivo da coima, corre junto de um tribunal judicial (n. $\left.{ }^{\circ} 1\right)$, por iniciativa do representante do Ministério Público, "aplicando se com as necessárias adaptações o disposto no Código de Processo Penal, sobre a execução da multa" nn. $^{\circ} 2$ do artigo 89. ${ }^{\circ}$, em sede do RJCE não é assim, pois o processo de execução da coima é um "processo de execução fiscal, da competência da AT" (artigo 64.).

Em síntese, o processo de execução por falta de pagamento da coima passou a ter natureza fiscal, com a especificidade de a cobrança coerciva da coima poder ser levada a cabo por agente de execução, na sequência da elaboração de protocolos com a Ordem dos Solicitadores e Agentes de Execução $\ln$. $^{\circ} 3$ do artigo 64.\%. Para tanto, aqueles terão os direitos assegurados nos restantes números do artigo $64^{\circ}$ e que, por princípio, pertencem exclusivamente aos funcionários da AT. De referir, ainda que em jeito telegráfico, que o novel artigo $64 .^{\circ}$, no seu n. 1 , refere se a uma certidão, a de dívida, "extraída nos termos do Código do Procedimento Administrativo e do Processo Tributário". Foi, pois, completamente, cilindrado o regime do artigo 89. do RGCO, porquanto, como já se disse, aí se dispõe que, nesta matéria, se aplica, com as necessárias adaptações, o disposto no CPP, sobre a execução da multa.

Não podemos concordar com esta nova modalidade de execução do pagamento da coima que não foi atempada e voluntariamente paga, pois que ela não só derroga o regime previsto no RGCO, como também o legislador do RJCE não explica a razão para ter subtraído esta competência ao Ministério Público le, em última instância ao Tribunal Judicial), para a entregar à AT, alterando a natureza da execução.

4.6. É tempo de concluir, sendo certo que não fomos exaustivos, nem o podíamos ser. Confessamos que a nossa expectativa, relativamente a este diploma, no sentido de contribuir para uma maior simplificação e melhoria dos regimes contra ordenacionais, chegou a existir em nós, e dela demos conta (VILELA, 2021, 438). Pelo que ora vimos, pensamos que tais expectativas foram goradas. Não obstante, um estudo com maior desenvolvimento e maior profundidade deste diploma é necessário, a fim de confirmarmos, ou não, esta nossa primeira opinião.

De qualquer modo, e porque importa, igualmente, louvar o que deve ser, aplaudimos a previsão expressa do instituto da atenuação especial da coima, no artigo $23 .^{\circ}$, bem como a previsão expressa do artigo $24 .^{\circ}$, onde se encontra a reincidência, instituto que há muito deveria constar do RGCO, mas que dele continua ausente. Este, pois, um primeiro e rápido pensamento sobre o RJCE. 
DOI: $10.46294 /$ ulplr-rdulp.siv 1 a 8

\section{Bibliografia}

ACHENBACH, Hans (2008), «Ahndung materiell sozialschädlichen Verhaltens durch bloße Geldbuße? Zur Entwicklung und Problematik "großer« WirtschaftsOrdnungswidrigkeiten», in: GA, 1, 1-17;

AZEVEDO, Tiago Lopes de (2020), Lições de Direito das Contraordenações, Coimbra: Almedina;

COSTA, José de Faria (2017), Direito Penal, Lisboa: Imprensa nacional casa da Moeda;

DIAS, Augusto Silva (2018), Direito das Contra ordenações, Coimbra: Almedina;

DUARTE, Maria Luísa (2021), Direito da União Europeia, Lições desenvolvidas, Lisboa: Associação Académica da Faculdade de Direito de Lisboa;

GORJÃO HENRIQUES, Miguel (2021), Direito da União - História, Direito, Cidadania, Mercado Interno e Concorrência, 2019, reimpressão, Coimbra: Almedina; MARQUES, Nuno Castro (2019), Contributo Para a Autonomia do Direito Nacional da Concorrência, Porto: Universidade Católica Editora do Porto;

SERRA, Teresa, "Contra ordenações: responsabilidade de entidades colectivas». In: RPCC, 1, 1999, p. 187-212;

SOUSA, Susana Aires de (2010), "A infracção fiscal (e a sua natureza) no direito português: breve percurso histórico, in: Boletim de Ciências Económicas, Volume LIII, 39 59 (acedido em: https://digitalis-dsp.uc.pt/bitstream/10316.2/24712/1/BoletimLIII_Artigo2.pdf?̣|n=pt-pt );

VILELA, Alexandra, O direito de mera ordenação social: entre a ideia de "recorrência" e a de "erosão" do Direito Penal Clássico, Coimbra: Coimbra Editora, 2013;

«Responsabilidade contra ordenacional da Pessoa Colectiva» (2020) in: Novos Estudos sobre Law Enforcement, Compliance e Direito Penal, Coord.

Científ. Maria Fernanda Palma, Augusto Silva Dias e Paulo Sousa Mendes, Coimbra: Edições Almedina, 2020, pp. 395 415;

"O direito das contra-ordenações necessário para um combate eficaz da corrupção», in: Corrupção em Portugal. Avaliação legislativa e proposta de reforma, Org. Albuquerque, Paulo Pinto de, Cardoso, Rui, Moura, Sónia, Lisboa: Universidade Católica Editora, 2021, pp. $429-438$. 